\title{
Instrumentos jurídicos para la protección y restitución de tierras despojadas o abandonadas forzosamente ${ }^{1}$
}

\section{Legal Instruments for the Protection and Restitution of Land and Abandoned Stripped Necessarily}

Alberto Álvarez Silva ${ }^{2}$

Fecha de Recepción: 7 de marzo de 2016

Fecha de Aprobación: 21 de junio de 2016

\section{RESUMEN}

¿Son coherentes y efectivas las herramientas jurídicas que tiene la Ley 1448 de 2011 para lograr la restitución integral de tierras a las víctimas de despojo y abandono forzado en Colombia? En Colombia se ha establecido que existen aproximadamente 4 millones de personas víctimas de despojo de tierras, y 6,5 millones de hectáreas abandonadas forzosamente. Por un lado, la Ley 1448 de 2011 tiene como objetivo reparar integralmente a las víctimas, pero por otro impone condiciones que reducen el alcance de dicha reparación integral en cuanto a quienes pueden ser beneficiarios y en cuanto a las posibilidades reales para acceder a la restitución, como por ejemplo que se incluyan propuestas claras dentro de los planes de desarrollo territoriales. Del éxito de la aplicación de la Ley de víctimas y restitución de tierras dependerá también el éxito de las medidas jurídicas y políticas que ha creado el Gobierno del presidente

1 Este artículo es resultado del proyecto de investigación titulado INSTRUMENTOS JURÍDICOS PARA LA PROTECCIÓN Y RESTITUCIÓN, el cual hace parte de los proyectos de investigación institucionales de la Corporación Universitaria Republicana.

2 Magister en Derechos Humanos y Derecho Internacional de los Conflictos Armados D.I.C.A. de la Escuela Superior de Guerra. Abogado y Especialista en Procesal Constitucional y Derecho Comercial de la Corporación Universitaria Republicana. Docente de la citada Academia. Correo electrónico: alberas2259@hotmail.com 
colombiano, Juan Manuel Santos, para alcanzar la paz nacional, las cuales suponen la existencia de un escenario de posconflicto que aún está muy alejado de la realidad de Colombia. Por esa razón, la restitución a las víctimas no cuenta con el escenario ideal para ser una realidad.

Palabras clave: Restitución, tierras, víctimas, despojo, violencia y reparación.

\section{Abstract}

Are coherent and effective legal tools that have the Law 1448 of 2011 to achieve comprehensive land restitution to victims of dispossession and forced abandonment in Colombia? In Colombia it has been established that there are approximately 4 million victims of dispossession of land and 6.5 million hectares necessarily abandoned. On the one hand the 1448 Act of 2011 aims to fully compensate the victims, but otherwise imposes conditions that reduce the extent of such reparation as to who may be beneficiaries as to the real possibilities for access to restitution, such that clear proposals within the territorial development plans are included. The successful implementation of the Law on victims and land restitution also depend on the success of legal and policy measures that created the government of President Santos to achieve national peace, which assume the existence of a post-conflict scenario which It is still far removed from the reality of Colombia, why restitution to victims does not have the ideal scenario a reality.

Keywords: Restitution, land, victims, dispossession, violence and repair.

\section{INTRODUCCIÓN}

El tema que se desarrollará en este artículo se refiere a la restitución de tierras en Colombia como componente del derecho a la reparación, y la manera en la que el Gobierno ha enfrentado el problema de las víctimas que han sido despojadas o forzadas a abandonar sus tierras. Este problema no es nuevo y, sin embargo, parece que así lo fuera, dado el entusiasmo inicial del Gobierno actual que impresionó y dejó a la opinión pública, e incluso a académicos y expertos en el tema, a la expectativa por el cumplimiento de las ambiciosas metas que se trazaron con la adopción de un nuevo cuerpo normativo consignado en la Ley 1448 de 2011, o Ley de Víctimas y Resti- 
tución de Tierras, que en adelante se denominará LVRT. No obstante, ya pasados tres ańos de aplicación de esta ley, se ha evidenciado que existen muchos obstáculos para lograr una reparación integral en cuanto al daño que han sufrido las víctimas de despojo y abandono forzado de tierras.

Antes de la vigencia de la LVRT, en el país ya se habían proferido dos leyes importantes que abonaron el camino hacia una política que hoy se trata de consolidar. Estas leyes son la 387 de 1997, sobre desplazamiento forzado, y la 975 de 2005, o Ley de Justicia y Paz. Son leyes que han tratado de reparar a las víctimas desde perspectivas diversas, pero que esencialmente se han enfocado en el mismo objetivo: ofrecer justicia y medidas que reparen a las víctimas.

La pregunta de investigación que se tratará de resolver es: ¿ Son coherentes y efectivas las herramientas jurídicas que tiene la Ley 1448 de 2011 para lograr la restitución integral de tierras a las víctimas de despojo y abandono forzado en Colombia? Igualmente, con esto se pretende también sostener que, debido a esa incoherencia interna y externa, las medidas o herramientas ofrecidas por la LVRT no han sido suficientes y no lo serán en lo que queda de tiempo de vigencia de la misma para reparar de manera integral a las víctimas del despojo y abandono forzado de tierras en Colombia.

Con la realización del presente trabajo se pretende encontrar los principales y más graves vacíos normativos y las falencias jurídicas de la LVRT. Igualmente, se busca conocer y determinar la normatividad que resulta necesaria para completar y fortalecer la aplicación de la LVRT para que los procesos de restitución sean exitosos. Finalmente, se llegará a identificar otros factores que son ajenos al ámbito jurídico legal, pero que son determinantes a la hora de lograr que los procesos de restitución sean eficaces.

Para la realización del trabajo se llevó a cabo un examen y análisis deductivo de la LVRT y de sus decretos reglamentarios, como también se observó las conclusiones de las organizaciones no gubernamentales que hacen seguimiento al cumplimiento de la LVRT. Como herramientas se acudió a testimonios de víctimas de despojo y abandono forzado, también al análisis de las sentencias proferidas por los Juzgados especializados en restitución de tierras. 


\section{Marco Histórico SObre la RESTITUCión de TIERRAS}

\section{Reformas y contrarreformas en Colombia}

La forma en que un Estado organiza o dispone de la tierra para que esta sea útil para la sociedad puede ser la causa y a la vez la respuesta a muchos males presentes en varios aspectos de la vida como el social, político y económico. Por eso, cuando en una sociedad como la nuestra existen varios problemas en torno al tema de la tierra, tales como un alto nivel de concentración de la misma, problemas de productividad, uso ineficiente del suelo, índices elevados de pobreza en la población rural, debilitamiento de la institucionalidad para solucionar los problemas rurales, entre otros (Franco Cańas \& De los Ríos Carmenado, 2011), lo que se busca es implementar soluciones a dichos problemas a través de una Reforma Agraria.

Es así como en la época Colonial, en el año de 1591, se dió la primera reforma agraria, por Felipe II, quien dispuso que la tierra debería darse a quienes la trabajaban (Mendoza Morales , 1998), pero los colonos, según Malagón (2005), frente a esta decisión opusieron el "recurso de suplicación, o mejor conocido como el se obedece pero no se cumple que consistía en una suspensión provisional de los actos de Gobierno, por considerarlos contrarios a la realidad americana" (p. 3).

Siguiendo a Mendoza (1998) se puede hablar de una segunda reforma agraria. Consistió en que los jesuitas convirtieron las "reducciones", a las que habían huido los indígenas perseguidos y asediados por los conquistadores españoles, en haciendas comunitarias, divididas en dos partes: una, llamada el campo de Dios, que era un terreno que se trabajaba y cuyos frutos eran para el beneficio colectivo, y, la otra, llamada el Campo del Hombre, la cual era de apropiación individual pues estaba dividida en lotes para cada miembro de la comunidad, los cuales no se podían enajenar pero sí usufructuar (Liévano Aguirre, 1996). Las tierras en donde los Jesuitas adelantaban sus Misiones eran realengas, es decir, que pertenecían al Estado y algunas otras eran legados que los particulares les otorgaban. Sin embargo, esta situación de prosperidad para los indios terminó cuando los jesuitas fueron expulsados de América en 1767 por decreto del Rey Carlos III, y les fueron expropiadas las haciendas, cuyas tierras fueron compradas por quienes tenían dinero, es decir, los latifundistas (Mendoza Morales, 1998). 
Una tercera reforma agraria, según Mendoza (1998), fue impulsada por el oidor Antonio Mon y Velarde en 1785, mediante la cual "organizó la población, expropió tierras, las repartió, creo pueblos, escuelas agrarias y fijó cuotas de producción” (pág. 3).

La cuarta reforma agraria vendría en la época de transición de la Colonia al Estado Republicano, en la cual los dirigentes tenían el propósito de eliminar varias instituciones del Colonialismo, entre ellas los resguardos indígenas. En 1810 se autorizó vender las tierras de los resguardos indígenas. Sin embargo, según Gutierrez Ramos (2002), se presentaron muchos obstáculos para repartir las tierras puestas en venta. Frente a la mencionada autorización, se opuso el Libertador, quien mediante "decreto 5 de junio de 1820 ordenó devolver a los naturales, como propietarios legitimos, todas las tierras que forman los resguardos, según los títulos, cualquiera que sea el que aleguen para poseerlas los actuales tenedores" (Mendoza Morales, 1998, pág. 3).

La quinta reforma agraria se presentó en 1850 con otro intento del liberalismo por eliminar los resguardos indígenas mediante la ley del 22 de junio, que ordenó la libre enajenación de estas tierras (Mendoza Morales, 1998).

En general, en el siglo XIX hubo muchos intentos por disolver los resguardos indígenas, como también Gobiernos que los restauraron y crearon de nuevo, a la vez que la resistencia indígena seguía luchando por conservar sus territorios.

Una sexta reforma dentro del siglo XIX, según Mendoza (1998), fue hecha por Tomás Cipriano de Mosquera, quien "decretó la expropiación de los bienes de la Iglesia; desamortizó los bienes llamados de manos muertas y pretendió traspasarlos a pequeños propietarios" (pág. 3). Aunque la reforma fue muy loable y parecía una salida al régimen del latifundio, las tierras liberadas terminaron en manos de terratenientes, comerciantes y políticos. Es decir, se presentó la misma situación que cuando los jesuitas fueron expropiados: la tierra quedó en manos de personas que no la trabajaban, o sea de los latifundistas y comerciantes, quienes veían en la tierra un bien comercial, más no consideraban que la tierra debía explotarse de forma racional y que de esa manera llegaría a beneficiar directamente a quienes trabajaban la tierra y crearía progreso para la sociedad en general. 


\section{Reformas agrarias en el siglo XX}

En el siglo XX se registraron dos importantes reformas agrarias. La primera se realizó dentro del Gobierno de Alfonso López Pumarejo mediante la ley 200 de 1936, la cual se caracterizó por haber introducido al ordenamiento jurídico la función social de la tierra. Según Franco \& De los Ríos (2011) lo que perseguía esta ley era "corregir la problemática de dominio y concentración rural” (pág. 102), a través de la instauración de "un régimen adecuado de tenencia y explotación de tierras" (Albán, 2011, pág. 344). Una herramienta que creó dicha ley para lograr su cometido fue la figura de la extinción de dominio para los terrenos baldíos, cuya finalidad era distribuir dichas tierras para explotarlas de manera racional siguiendo el principio de la función social económica de la propiedad. Pero según Machado (como se cita en Albán, 2011), la reforma de la Ley 200 utilizó la figura de la extinción de dominio para impulsar "a los latifundistas a elevar la productividad en un término de diez años" (pág. 345), mas no para modernizar las métodos de producción agraria y adecuarlos a la lógica del capitalismo industrial, y ponerle límites al aprovechamiento que a través de la renta realizaban los latifundistas sobre la tierra. Tampoco sirvió para resolver el problema de la concentración de la tierra. Sin embargo, hubo un avance en el sentido de que se reconoció el derecho de los trabajadores del campo a la posesión de las tierras. Para Balcázar, López, Orozco \& Vega (como se citan en Franco Cańas \& De los Ríos, 2011, p.102) otros de los beneficios de la Ley 200 consistieron en legalizar algunas tierras sobre las cuales era dudosa su titulación y facilitar a los arrendatarios la adquisición de parcelas y a los colonos la legalización de su posesión. Sin embargo, a pesar de sus aparentes bondades y avances, según Mendoza (1998), esta Ley de origen liberal enfrentó muchos obstáculos en su aplicación, por parte de muchos políticos, incluso algunos liberales, quienes "amenazaron con lanzarse a la guerra civil si se aplicaba" (pág. 3).

Igualmente, no se puede desconocer que con la Segunda Guerra Mundial el proceso de industrialización que se pretendía iniciar en el país se frustró y, con él, la reforma agraria pasó a un segundo plano, pues la preocupación principal era sustituir las importaciones de alimentos y materias primas incrementando la producción agrícola, sin importar si los métodos de producción seguían siendo arcaicos o si las tierras seguían en manos de latifundistas y comerciantes (Albán, 2011). Ya que la idea era 
incrementar y fomentar la producción interna, en el Gobierno de Eduardo Santos se pensó en "abaratar las materias primas y los alimentos" (Albán, 2011, pág. 345). Sin embargo, esta estrategia no funcionó para impulsar la industrialización.

En 1944, dentro del segundo mandato de Alfonso López Pumarejo, se promulgó la Ley 100, que fue una prolongación de la Ley 200 de 1936, ya que continuó el modelo de explotación agrícola a través de parcelaciones con el fin de incrementar la producción, pero introdujo algunas novedades como "declarar de conveniencia pública el incremento del cultivo de tierras y de la producción agrícola a través de sistemas que implicaran una coparticipación en los productos entre el arrendador o dueño de las tierras y el cultivador" (Ley 100 de 1944, artículo $1^{\circ}$ ). Estos sistemas de coparticipación eran los "contratos de aparcería" y los conocidos según la región como contratos de agregados "poramberos, arrendatarios de parcelas, vivientes mediasqueros, cosecheros" (Ley 100, 1944, art. 1). También se dispuso de nuevo la adjudicación de tierras en propiedad o bajo derecho de usufructo o arrendamiento a quienes trabajaran la tierra y comprobaran su capacidad para explotarlas económicamente y se declaró como de utilidad pública e interés social la adquisición por el Estado de tierras no cultivadas o insuficientemente explotadas por los particulares, con el fin de ser parceladas (Ley 100, 1944, arts. 17 y 18). También es de resaltar que esta ley imponía a los cultivadores la especie de cultivo por desarrollar, la organización, dirección y métodos de cultivo que se establecieran y los sistemas de control y vigilancia sobre las tareas de explotación (Ley 100, 1944, art. 21).

Entonces, al haber fortalecido la Ley 100 de 1944 los contratos de aparcería, se frenó el intento de transformar el régimen de latifundios y se continuó favoreciendo los intereses de los terratenientes y especuladores de tierras y, con ello, se retrasaba el proceso de industrialización capitalista, y se creaba el clima perfecto para generar más conflictos sociales.

\section{Origen de los conflictos sociales a causa de la propiedad y tenencia de la tierra}

Los campesinos que trabajaban la tierra y que no se habían beneficiado realmente de las reformas de 1936 y 1944 se alzaron contra los propietarios y poseedores de tie- 
rras. Estas luchas y protestan se fueron transformando en movimientos políticos de corte liberal, mientras que los conservadores representaban los intereses de quienes se habían beneficiado con dichas reformas, es decir, los latifundistas, comerciantes y especuladores. Así surgieron los partidos políticos.

Con la Ley 135 de 1961 se crearon instituciones y organismos encargados de ejecutar la política estatal de reforma agraria. En cuanto al andamiaje institucional, la Ley 135 creó el Instituto Colombiano de Reforma Agraria - INCORA, el Consejo Social Agrario - CNA, el Fondo Nacional Agrario - FNA, además de los procuradores agrarios. También dispuso las condiciones para la creación de las Corporaciones Regionales de Desarrollo. Dentro de sus objetivos, los más importantes que vale la pena resaltar son: (1) reformar la estructura agraria a través de procedimientos dirigidos a corregir el problema de la concentración de la propiedad y su fraccionamiento antieconómico, como también reconstruir unidades de explotación en las zonas de minifundios y dotar de tierras a las que no la posean, prefiriendo a quienes directamente la exploten o la trabajen; (2) fomentar una adecuada explotación de la tierra inculta o deficientemente utilizada, a través de programas que provean su distribución ordenada y racional aprovechamiento; (3) aplicar técnicas adecuadas para aumentar la productividad y destinar las tierras al uso que sea coherente con su ubicación y características; y (4) que se crearan condiciones para que los pequeños arrendatarios y aparceros gozaran de mejores garantías, y para que estos, junto con los asalariados agrícolas, accedieran más fácilmente a la propiedad de la tierra.

En el año de 1968 se promulgó la Ley 1a , la cual respondió, por una parte, al requerimiento de hacer los procedimientos más ágiles con la introducción de la extinción de dominio por vía administrativa y, por otra parte, a la exigencia de brindar más garantías y mejores condiciones de vida al aparcero con la entrega de tierras trabajadas por ellos. Según Balcázar et al (2001), la Ley 1a de 1968, también llamada de Arrendatarios y Aparceros, fijó nuevas causales de expropiación y reglamentó las Unidades Agrícolas Familiares que había creado la Ley 135 de 1961, con el fin "de proteger y regular la tenencia y explotación de las porciones de tierra distribuidas individualmente a los campesinos beneficiarios principalmente en lo relacionado con su venta o transferencia" (pág. 13). Otro aporte importante de la Ley $1^{a}$ de 1968, según Machado y Suárez (como se citan en Franco Cańas \& De los Ríos Carmenado, 2011) es que facilitó la comunicación entre los campesinos y el Estado con "la 
creación de la Asociación Nacional de Usuarios Campesinos (ANUC)" (pág. 104). Sin embargo, con esta ley tampoco se cumplió con el objetivo de convertir en propietarios a arrendatarios y aparceros, pues "los propietarios reaccionaron desalojándolos de sus predios para evitar que solicitaran la adjudicación de las tierras que trabajaban, o iniciaran reclamaciones por el pago de "mejoras" realizadas por ellos en los predios" (Balcázar et al, 2001, pág. 13). Entre tanto, la vida en el campo se tornaba más violenta y peligrosa para los campesinos trabajadores por la presencia de los grupos de guerrillas y paramilitares, quienes, además, imponían la siembra de cultivos ilícitos (Franco Cañas \& De los Ríos Carmenado, 2011, pág. 104). Esto último inevitablemente conllevó a la concentración de la propiedad, es decir, el régimen latifundista se reafirmó. Respecto del objetivo de lograr la redistribución de tierras a cargo del INCORA, según Balcázar et al (2001), se frustró porque "de un poco más de 71.000 aparceros inscritos en 1.968 aspirando a 514.000 hectáreas, apenas se adquiere (por parte del INCORA) el 20 por ciento de las tierras para beneficiar al 12 por ciento de los aspirantes"(pág. 13).

Como respuesta a la reforma de la Ley $1^{\circ}$ de 1968, según Mendoza (1998), en 1972 con un enfoque más capitalista e industrial, "un grupo de propietarios reunidos en Chicoral, Tolima, suscribió un pacto, conocido como "el chicoralazo", modelo eficiente de contrarreforma agraria; cortó de raíz el proceso iniciado por el presidente Lleras Restrepo. El tema agrario desapareció insumido en el juego de intereses largamente arraigado, como hemos visto" (pág. 3). Así el Gobierno presentó un proyecto de Ley que se convertiría en la Ley $4^{a}$ de 1973 , la cual incluía nuevos criterios para determinar si un predio se encontraba adecuadamente explotado, estableciendo niveles mínimos de productividad. Sin embargo, dichos criterios en la práctica no se aplicaron por el INCORA "por razones técnicas y por no contar con un censo agrícola detallado y actualizado" (Franco Cańas \& De los Ríos Carmenado, 2011, pág. 105). También se contempló la negociación directa para la adquisición de tierras, y se agilizó el proceso para la adjudicación de tierras a los beneficiarios (Balcázar et al, 2001).

En el Gobierno de Belisario Betancur se promulgó la Ley 35 de 1982 que, si bien se dictó dentro de un contexto de conflicto político con el fin de restablecer y preservar la paz con grupos rebeldes, contenía normas que afectaban la distribución de tierras, pues las personas indultadas en virtud de la ley 35 de 1982 se convertían en beneficiarias de los programas de dotación de tierras y vivienda rural, entre otros. 
Para lo cual, según Balcázar et al (2001), por medio del Decreto Ley 222 se autorizó al INCORA para que pudiera "negociar y comprar tierras con precios inferiores al avalúo comercial fijado por el Instituto Geográfico Agustín Codazzi, pero efectuando el pago en un menor plazo" (pág. 16). La Ley 35 de 1982 con los correspondientes decretos que la reglamentaron (Decreto reglamentario 3287 de 1987 y Decreto Ley 222 de 1983) tuvo un pequeño avance en comparación con lo ocurrido bajo la Ley 4 de 1973, ya que de 121.860 hectáreas ingresadas al Fondo Nacional Agrario bajo esta ley, ingresaron 139.412 bajo la ley 35 de 1982. Igualmente, el número de familias beneficiadas con los programas institucionales aumentaron, ya que bajo la Ley 4 de 1973 fueron de 6.770 y con la aplicación de la ley 35 de 1982 las familias beneficiadas fueron de 8.016 (Balcázar et al, 2001).

Posteriormente, se promulgó la Ley 30 de 1988. Según Albán (2011), esta tuvo como objetivos "lograr una acción más coordinada de las instituciones del gobierno, elevar el nivel de vida de los campesinos, simplificar los trámites de adquisición y dotación de tierras, eliminar la calificación de las tierras y dar mayores instrumentos al INCORA para el desarrollo de sus programas" (pág. 351). Esta Ley se crea con el principal objetivo de fomentar la adecuada explotación y la utilización social de las tierras rurales aptas para la explotación agropecuaria y de las incultas, ociosas o deficientemente utilizadas, mediante programas que provean su distribución ordenada, su incorporación al área de explotación económica agraria y su racional aprovechamiento (Ley 30,1968, num. 2, art. 1). Para Balcázar et al (2001), en la vigencia de la Ley 30 de 1968 se observó una reactivación de la reforma agraria en cuanto al tema de tierras por parte del INCORA, ya que un 80 por ciento de las 575.756 hectáreas que ingresaron al Fondo Nacional Agrario fueron por concepto de compras, "mientras que las expropiaciones y cesiones se reducían considerablemente. Al tiempo, que el número de familias beneficiadas se elevó a 33.670" (pág. 16).

A diferencia de las leyes anteriores, la Ley 30 de 1988 hizo que el concepto de reforma agraria cambiara, porque como sostienen Franco Cañas \& De los Ríos Carmenado (2011) ya no era un mecanismo que afectara la estructura agraria a través de "la acción de expropiación y redistribución de terrenos baldíos, sino a través de la compra institucional de tierras y su redistribución a los campesinos beneficiados" (pág. 107). A pesar de esta reactivación mediante la modalidad de compra, Balcázar et al (2001) afirman que "los resultados obtenidos son todavía muy precarios, si se tiene 
en cuenta que apenas se benefició al 3.8 por ciento de las familias sin tierra o que no poseen áreas suficientes" (pág. 17). Por tanto, lo que evidenció la experiencia con la aplicación de la Ley 30 de 1988 fue que a pesar del aumento en la compra de tierras, esta no redundó en mayores beneficios para las familias sin tierras y que el problema de la concentración continuaba sin una solución realmente efectiva.

Ante este panorama, el Gobierno decidió a través de la promulgación de la Ley 160 de 1994 crear el Sistema Nacional de Reforma Agraria y Desarrollo Rural para el desarrollo de la economía campesina y para promover el acceso progresivo a la propiedad de la tierra de los trabajadores agrarios (Ley 160 de 1994, artículo 2). Con esta Ley el Estado decide no entregar tierras de manera gratuita a todos los que no fueran propietarios, sino solo a aquellos que no tuvieran suficiente extensión de tierra cuando se tratara de minorías étnicas, o a quienes hubieran sobrevivido a calamidades públicas naturales o para quienes el Gobierno cree programas especiales de dotación de tierras o zonas de manejo especial o que estén en zonas de interés ecológico (Ley 160, 1994, art. 31). La principal forma para que campesinos adquirieran tierras bajo la Ley 160 de 1994 fue la compra directa con el otorgamiento de créditos y subsidios entregados por el Estado a través de entidades financieras. Por eso autores como Balcázar et al (2001) y Franco Cañas \& De los Ríos Carmenado (2011) afirman que con la Ley 160 se introdujo el mercado de tierras para dinamizar la distribución de las mismas. Es decir, hubo un cambio en la política económica hacia un neoliberalismo en donde el Estado se abstenía de intervenir directamente y dejaba que el mismo mercado a través de la oferta y la demanda se encargaran de redistribuir la propiedad, pero con la existencia de subsidios y créditos. Un avance que se logró con la Ley 160 de 1994 fue que generó nuevos espacios para la concertación entre Gobierno y campesinos a partir de la creación de los Comités Departamentales de Desarrollo Rural y Reforma Agraria. Sin embargo, según Balcázar et al (2001), el resultado de la aplicación de esta ley tampoco produjo un cambio significativo en la redistribución de la propiedad, pues ingresaron 286.939 hectáreas al Fondo Nacional Agrario y las familias beneficiarias fueron 19.397, cifras que son considerablemente más bajas que las que se dieron bajo la Ley 30 de 1988.

Luego de la Ley 160 de 1994, se expidió por el Ministerio de Agricultura y Desarrollo Rural el Decreto 1300 de 2003, por el cual se creó el Instituto Colombiano de Desarrollo Rural que reemplazó al INCORA, y se promulgó la Ley 1152 de 2007, 
por medio de la cual se dictó el Estatuto de Desarrollo Rural, y se reformó el INCODER. Según Franco Cańas \& De los Ríos Carmenado (2011), el mercado de tierras se mantuvo; sin embargo, variaron las condiciones en las que se subsidia, al ser ahora de forma total o parcial (dependiendo de las condiciones económicas de los beneficiarios) por el Estado, y la coordinación de la entidades que esta vez es realizada por el INCODER" (pág. 109).

\section{Situaciones de despojo en Colombia ocurridas antes}

\section{de la ley 1448 de 2011}

Algunos de los casos más representativos de despojo ocurridos en Colombia fuera del contexto de las reformas y contrarreformas agrarias son:

a. Procesos de despojo ocurridos en Córdoba, Sucre y la Región de Montes de María, desde los años 20 propiciados por la conformación de haciendas ganaderas por parte de grandes propietarios de tierras quienes a través de presiones, engaños y de homicidios a campesinos e indígenas se apropiaron de sus tierras.

El despojo entendido como se describe en el artículo 74 de la Ley 1448 de 2011 como una "acción por medio de la cual, aprovechándose de la situación de violencia, se priva arbitrariamente a una persona de su propiedad, posesión u ocupación, ya sea de hecho, mediante negocio jurídico, acto administrativo, sentencia, o mediante la comisión de delitos asociados a la situación de violencia”, es algo que ha ocurrido varias décadas anteriores al primero de enero de 1991, que es la fecha a partir de la cual la Ley 1448 de 2011 reconoce como titulares del derecho de restitución a aquellos propietarios o poseedores de predios, o explotadores de baldíos, que hayan sido despojados de sus tierras por violaciones al derecho internacional humanitario o a las normas internacionales de derechos humanos dentro del contexto del conflicto armado interno colombiano.

Una investigación hecha por el Grupo de Memoria Histórica de la Comisión Nacional de Reparación y Reconciliación, cuyo trabajo quedó consignado en el informe "La tierra en disputa Memorias de despojo y resistencia campesina en 
la costa Caribe (1960-2010)", da cuenta de los problemas de despojo de la tierra en Colombia, durante el Siglo XX. Según el este informe, en los años 20 la hacienda era un medio de explotación de la tierra, el cual se centraba en ese entonces en la producción de tabaco y ganadería, pero las tierras se obtenían a través del despojo a los campesinos, quienes "se vieron obligados a desplazarse a zonas de colonización, ubicadas en zonas montañosas, como los Montes de María, y los valles altos de los ríos Sinú y San Jorge" (Grupo de Memoria Histórica, 2010, pág. 64). Este fenómeno fue evolucionando y haciéndose más complejo hasta llegar a un proceso que se conoció como la Ley de los tres pasos, en el cual la tierra es explotada de forma indiscriminada por el colono, hasta que la vende o cede a un finquero o comerciante que semiexplota el terreno o fundo, con la idea de integrar otros lotes y consolidar la explotación de la tierra, pero quien finalmente termina por ceder el fundo a un latifundista quien a su vez tiene el propósito de crear una nueva hacienda (Grupo de Memoria Histórica, 2010). Esta forma de apropiación de la tierra se caracterizaba por presiones, engaños y muertes, y fue la que dio lugar a la primera etapa de despojo de tierra en el siglo XX en Colombia, sobre todo en la zona de Córdoba.

Para finales de los años 40, la mayoría de la tierra en Córdoba había sido apropiada a través del despojo, y antes de la época de la Violencia era aceptado como una práctica permanente de los grandes propietarios de tierras contra los campesinos e indígenas.

b. Luego vendría la época de la Violencia entre partidos políticos, la cual surgió a manera de reacción por parte de los campesinos e indígenas frente a la manera violenta y arbitraria como los grandes propietarios habían consolidado sus haciendas, con el consentimiento del Estado. Se generaron enfrentamientos, entre los hacendados de los partidos tradicionales y los campesinos que integraban en su mayoría las guerrillas liberales, por la tenencia y control de la tierra.

c. En los años 60, surgieron las Fuerzas Armadas Revolucionarias de Colombia (FARC), quienes apoyadas en lo que llamaron "Programa Agrario de los Guerrilleros" se propusieron ocupar y recuperar la tierra despojada, dentro de su ideal de democratizar la sociedad. En desarrollo de dicho programa, en febrero 21 de 1971, se llevaron a cabo más de ochocientas ocupaciones de predios 
en el país. Este proceso de recuperación de tierras era tolerado e incentivado por muchos sectores de la sociedad (Grupo de Memoria Histórica, 2010). Aunque esta era entendida como una lucha democrática por la tierra, en un sentido estricto fue otro momento de la historia de Colombia, en el cual se llevaron a cabo muchos despojos de manera sistemática y violenta.

d. En los años 80, en la zona de los Llanos orientales, concretamente en los departamentos del Meta y Casanare, el despojo de tierras provenía de acciones a cargo de Gonzalo Rodríguez Gacha, alías "el Mexicano"; "Los Carranceros", quienes cuidaban las propiedades de Víctor Carranza y a su vez se apropiaban de tierras ubicadas desde el Meta hasta Paz de Ariporo y Hato Corozal por la fuerza o pagando por ellas precios irrisorios; y los Buitrago, quienes eran un grupo de autodefensa creado por Héctor Buitrago, quien se conoce como el fundador de las Autodefensas Campesinas del Casanare (El tiempo, 2014)

e. En los años 90, se realizaron acciones de despojo de tierras por parte de las Autodefensas Unidas de Colombia, y concretamente por el Bloque Centauros, en la zona del Río Ariari, cuando ya estaban organizadas, y por las Autodefensas Campesinas del Meta y del Vichada (ACMV) en el norte del Meta y Vichada (El tiempo, 2014).

Igualmente las AUC despojaron tierras en las zonas de Córdoba y Sucre, las aguas y playones en las Cíenagas de Martinica (Córdoba) y de San Benito Abad (Sucre), parcelas que habían sido adjudicadas a los campesinos por el Incora o Incoder, sobre todo en los Montes de María. (Grupo de Memoria Histórica, 2010).

También se evidenciaron casos de despojo a causa de la realización de megaproyectos, por ejemplo el desalojo indígena de Urrá (Córdoba), en donde se realizó la construcción de una represa.

Finalmente, en el informe "La tierra en disputa Memorias de despojo y resistencia campesina en la costa Caribe (1960-2010)", realizado por el Grupo de Memoria Histórica de la Comisión Nacional de Reparación y Reconciliación también se evidenciaron casos de abandono, ventas forzosas y compras masivas de tierras en Montes de María. 
Las FARC por su parte se apropiaron de tierras por la fuerza, a manera de estrategia de defensa con el fin de usarlas como corredor para movilizarse libremente. El mayor número de predios despojados se encuentra en zonas de influencia de los bloques Oriental y Sur,identificadas como el corredor de movilidad de dicho grupo armado.

\section{Situación actual de los despojados de tierras en Colombia}

Según el Plan Nacional de Desarrollo 2010 - 2014, se estableció que se han abandonado forzosamente en Colombia 6,5 millones de hectáreas de tierras. Según González Posso (2013), investigador del Centro de Memoria Histórica, con base en los datos registrados en el RUPD estableció que los predios abandonados "entre 1994 a 2002 no son inferiores a 400.000 , pertenecientes a 500.000 familias, ni inferiores a 10 millones de hectáreas" (pág. 4)

La situación de por lo menos 4 millones de víctimas de despojo va de la pobreza hasta pobreza extrema. Su situación es precaria, porque su sustento de vida lo obtenían de las actividades económicas que dependían de la tierra. Igualmente, se les arrebató el lugar que les daba una percepción de seguridad y la estabilidad social y económica necesaria para vivir dignamente.

Hasta 2014, según datos suministrados por el Director de la Unidad de Restitución de Tierras Seccional Córdoba, en todo el territorio nacional se habían beneficiado más de 1.500 personas con el proceso de restitución iniciado con la aplicación de la Ley 1448 de 2011, lo cual es una cifra bastante baja para los millones de víctimas de despojo que existen en el país.

\section{MODELO TEÓRICO PROPUESTO POR González Pulgarín \& Henao Guzmán (2012)}

Este modelo teórico es el resultado de la aplicación conjunta de las medidas que contiene la Ley 1448 de 2011 con las políticas económicas que estableció el Gobierno Nacional en el Plan Nacional de Desarrollo para el período de 2010 a 2014, y que fue aprobado mediante la Ley 1450 de 2011. Este es un modelo que genera concen- 
tración de la tierra y lo han llamado modelo de agencia, en el cual surge el problema de que no hay una verdadera confluencia de intereses entre el principal y el agente, en este caso, las víctimas del conflicto interno y el Estado, respectivamente. Teniendo en cuenta que la Ley 1448 de 2011 parte del supuesto que con la restitución de sus tierras las víctimas obtendrán una reparación integral al daño que han sufrido y lograrán una estabilización socioeconómica. En este sentido, la Ley 1448 de 2011 coincide con la Ley 160 de 1994, que establece una forma de distribución de tierra a partir de la creación de la Unidad Agrícola Familiar (UAF), que se conformará por campesinos y desplazados quienes pueden continuar trabajando la tierra y contribuir al desarrollo económico del país, y además dicta normas generales sobre distribución, adjudicación y uso de terrenos baldíos.

\section{Modelo de distribución de la tierra}

Un ejemplo de modelo de distribución de tierras se encuentra en las tierras públicas de la Patagonia. Según Bandieri (2005), este modelo de distribución consiste en transferir de manera sistemática tierras públicas a manos de particulares por medio de donaciones, venta o recompensas por servicios prestados a la Nación. Como consecuencia de la implementación de estas políticas, la tierra se concentró en pocas personas y las grandes propiedades se expandieron aún más, sobre todo por las campańas militares realizadas para apropiarse de territorios indígenas. En general, las tierras que adquirieron los particulares del Estado mediante la ganadería extensiva, resultó imponiendo un modelo de acumulación de tierras en manos de latifundistas.

\section{Jurisdicción del modelo de restitución de tierras}

La jurisdicción creada para llevar a cabo el proceso de restitución de tierras tiene como objetivo garantizar el reconocimiento y el cumplimiento de derechos de las víctimas del conflicto armado, entre ellos el derecho fundamental a la restitución y a la formalización de tierras y medidas complementarias dirigidas a reparar y transformar la vida de estos ciudadanos.

Según el Observatorio de Regulación de Derechos de Propiedad (2013), el juez responsable es aquel que cumple la Constitución, entendiendo que no puede serle fiel 
a una interpretación exegética ni histórica de las normas, sino que debe tener en cuenta su propio juicio normativo. Esta idea implica que el operador jurídico debe ser sensible no solo al contexto de creación, sino al de aplicación de la norma, y debe estar atento a las variaciones circunstanciales que por cuestiones de tiempo y modo pueden variar la forma de aplicar la norma (Observatorio, 2013)

En este sentido, están abiertos a las adaptaciones de la Constitución, modificaciones que son exigidas por nuevos contextos, por medio de consensos políticos más amplios, como es el caso de la Ley de Víctimas y Restitución de Tierras.

La Ley 1448 de 2011 creó una jurisdicción especial, con el objetivo de dar respuestas al despojo y abandono masivo de tierras en el marco del conflicto armado. Este instrumento es respaldado por el sistema jurídico colombiano en su totalidad, empezando por la Constitución Política y el llamado bloque de constitucionalidad, pasando por el Código Civil y la Ley 160 de 1994, el primero regulador de las situaciones sobre la propiedad de bienes muebles e inmuebles, y la segunda reguladora de la propiedad de bienes. (Observatorio, 2013).

Los jueces y magistrados especializados en restitución de tierras fueron instituidos para garantizar unos derechos particulares, especialmente el de la restitución y la normalización, al ser este un derecho fundamental, y que por ello exige la interpretación flexible de otras normas jurídicas que pudiesen resultar contrarias en tiempos ordinarios. Es así como la restitución es reconocida como un derecho fundamental, tanto por la Ley como por la jurisprudencia constitucional, resultando en que los fallos de los jueces se dirigen a la garantía y el goce efectivo de derechos inherentes a la restitución de la tierra.

Incluso, la preponderancia que ha tenido la jurisprudencia constitucional en el proceso de restitución, y que ha sido reforzada con frecuencia por las sentencias de restitución, es una muestra de que el quehacer de estos jueces corresponde efectivamente al de un juez constitucional.

En las sentencias de restitución, los jueces generalmente apelan a instrumentos internacionales de DD.HH. y a la jurisprudencia y doctrina constitucionales anteriores y posteriores a la expedición de la Ley 1448 de 2011 . Incluso, cuando la misma Ley le 
sirve de fundamento al juez para determinar la solución del caso concreto, los jueces recurren por lo general a interpretaciones constitucionales previas, debido a que la Ley incluye un gran catálogo de principios cuyo contenido no está determinado de antemano (Observatorio, 2013).

Al ser una norma con estas limitaciones, el juez de restitución debe desplegar un esfuerzo interpretativo y dirigirse a otros instrumentos legales, jurisprudenciales o constitucionales, para dar solución a los casos concretos que no son de fácil resolución, así como maniobrar el catálogo de principios que incluye la Ley.

\section{Justicia Transicional}

La jurisdicción de la ley de Restitución de Tierras, y su consiguiente reglamentación, se delimita por el marco de la Justicia Transicional. Tiene cinco presunciones, según las cuales se permitiría que la carga de la prueba recaiga directamente sobre los posibles despojadores y a las víctimas les baste con demostrar su propiedad, posesión u ocupación sobre los predios (2,3). Como es una Ley de restitución de tierras, más no una ley de reforma agraria, los tenedores no están incluidos como posibles beneficiarios.

En este marco normativo, se ha planteado un tratamiento diferencial para los grupos étnicos en Colombia, como es el caso de la población indígena y grupos pertenecientes a la población afrodescendiente, raizal o palenquera, y la población Rrom. En uno de los documentos de trabajo del Proyecto de Protección de Tierras y Patrimonio de la Población Desplazada, proyecto que entró en funcionamiento en el año 2003, se ha intentado sintetizar la legislación que debe ser tenida en cuenta en relación a la restitución en relación con los grupos étnicos (4). Aunque el documento recoge las leyes y otras reflexiones en relación al posible tratamiento diferenciado de los grupos étnicos, en realidad la ruta de protección de las tierras y de reparación no es muy distinta a la que se ha planteado cuando las afectaciones suceden para otras poblaciones rurales.

En lo que concierne a los pueblos indígenas, el Decreto 4800 del 20 de diciembre de 2011, que reglamenta la Ley, hace una mención particular en los artículos 216, sobre los informes periódicos de los programas de protección; artículo 217, sobre el proce- 
dimiento de la declaratoria de protección colectiva, ya que la población indígena es considerada Sujeto Colectivo de Derechos; artículo 223, sobre la reparación colectiva; y artículo 241, sobre la conformación de un Subcomité de Enfoque Diferencial.

Resumiendo, tanto el planteamiento de la Ley como su posterior reglamentación han evidenciado que lo que se considera como un enfoque diferencial son dos cosas: por un lado, el reconocimiento de que existe una legislación que cobija a los grupos étnicos, previa a la ley de tierras, y, por otro, que la atención y reparación debe contemplar a los pueblos indígenas como Sujetos Colectivos de Derechos.

\section{Soluciones propuestas al problema}

\section{Creación de una Comisión de la Verdad sobre tierras:}

Según Hernández (2011) "la búsqueda de la verdad no puede limitarse a la verdad judicial” (párr. 17), por eso se propone la creación de una comisión de la verdad sobre las tierras para que el derecho a la verdad sea real y efectivo como lo ordena la misma Ley 1448 de 2011.

La anterior propuesta la coadyuva la Comisión Colombiana de Justicia (citada en Verdad Abierta, 2012), quien ha manifestado que las confesiones de los paramilitares que se acogieron a la Ley 975 de 2005 no han revelado información suficiente sobre el "desplazamiento forzado como una forma de usurpar las tierras; tampoco han reconocido completa y adecuadamente su responsabilidad y no han brindado información que permita conocer la cadena de testaferrato conformada para la usurpación de los bienes" (párr. 19). Por eso propone, igualmente, que se cree una Comisión de la Verdad sobre las tierras que se encargue de llevar a cabo investigaciones sobre quienes fueron los responsables directos del despojo.

\section{Claridad y control sobre el destino de los bienes entregados por los desmovilizados:}

También se propone por parte de la Comisión Colombiana de Justicia que exista claridad y control sobre el desino de los bienes que entregan los desmovilizados, pues muchas veces estos bienes figuran al mismo tiempo dentro de procesos ordinarios de 
extinción de dominio y en procesos de reparación de víctimas por la Ley de Justicia y Paz, o se dan casos en que los bienes tuvieron problemas para ingresar al Fondo de Reparación de Víctimas, porque eran objeto de contratos de arrendamiento para el Programa de Proyectos Productivos por la Paz que contemplaba opciones laborales para los desmovilizados, campesinos y desplazados, y tuvo que intervenir la Corte Suprema de Justicia para ordenar su integración. (Verdad Abierta, 2012)

\section{Medidas que garanticen de manera efectiva la estabilización socioeconómica y el retorno:}

La investigadora Aura Bolívar Jaime del Centro de Estudios de Derecho, Justicia y Sociedad - DeJusticia propone que se deben implementar medidas que garanticen de manera efectiva la estabilización socioeconómica con el propósito de asegurar una restitución integral y efectiva a las víctimas, como también crear medidas efectivas para el retorno (Bolívar Jaime, 2012).

\section{Respuesta Estatal RESPECTO A LA LEY 1448 DE 2011.}

\section{Descripción de los problemas generados con la aplicación de la ley 1448 de 2011 y sus deficiencias:}

1. Anteriormente a la Ley 1448 de 2011 se creó una estructura estatal contenida en las leyes 418 de 1997; 548 de 1999; 782 de 2002; 1106 de 2006; 1421 de 2010; 1738 de 2014; el decreto 4436 de 2006, junto con la Ley 387 de 1997 sobre desplazamiento forzado que incluyó funciones dirigidas a entregar tierras para quienes fueron obligados a dejar las propias a causa de la violencia.

En la Ley 387 de 1997 el trámite estaba a cargo de la Red de solidaridad social, incluso desde entonces se empezaron a identificar a las víctimas para focalizar su atención, pero realmente no era otra cosa diferente a un intento por reconocerles sus derechos como víctimas. Lo importante es que con base en estas normas se entregaron bienes, entiéndase por esto que también se entregaron tierras, y también se llevaba un registro de las víctimas a cargo de la Red de 
Solidaridad Social y de los bienes rurales abandonados por los desplazados por la violencia a cargo del INCORA.

El problema es que la estructura creada sobre todo en beneficio de los desplazados por la violencia viene a ser sustituida o reemplazada por la ley 1448 de 2011, creando confusión para este grupo, además que se rompió la continuidad en los registros de víctimas y bienes, pues con la creación de nuevas entidades, la labor de investigación se reinicia, confundiendo a los desplazados dentro de un grupo más amplio y heterogéneo como lo son las víctimas del conflicto armado en sentido genérico.

2. La limitante del tiempo establecida en el artículo 75 de la ley 1448 de 2011 para reconocer a quienes pueden ser sujetos de la restitución de tierras, no considera que el despojo y abandono forzado tiene sus raíces desde antes del año de 1991.

3. Hasta el 1 de agosto de 2014 solo se habían restituido 29.695 hectáreas a comunidades campesinas, y 50.000 a indígenas, lo cual es una cifra bastante baja si se tiene en cuenta que el Gobierno fijó como meta devolver dos millones de hectáreas, al finalizar la vigencia de la ley 1448 de 2011, lo que ocurrirá en el año 2021. Esto quiere decir que la década establecida para aplicar la ley 1448 de 2011 no será suficiente para lograr efectividad respeto a la reparación de las víctimas de despojo y abandono forzado.

4. La Ley 1448 de 2011 contempla la existencia de un programa de retorno y reubicación para las víctimas de desplazamiento forzado, el cual no cuenta con la participación de las víctimas en su formulación y en el desarrollo del proceso como tal de retorno y reubicación. Además, persiste la falta de condiciones de seguridad para que las víctimas retornen a los lugares de origen.

5. Un grave problema que se ha evidenciado en el trámite de los procesos judiciales de restitución de tierras es que los jueces están priorizando el trámite de aquellos casos en que no existe opositor, lo cual implica que se trata de tierras abandonadas o baldíos, con lo cual no se está cumpliendo el objetivo de la Ley de Victimas y Restitución de Tierras, el cual es recuperar la tierra de posesio- 
nes o titulaciones falsas o fraudulentas que están en manos de terceros o de los victimarios y devolverlas a sus propietarios y poseedores legítimos.

6. Existen zonas especialmente difíciles, en donde se dificulta la restitución de tierras sin poner en alto grado de riesgo la vida de las víctimas, como los Montes de María, el Magdalena Medio y el Urabá antioqueño. A estas zonas hay que prestarles especial atención pues el Gobierno ordenó desde un inicio, priorizar la restitución de tierras en las mismas.

7. Un factor que hace que los procesos de restitución de tierras no sean tan rápidos como se espera es el hecho de que a pesar de que se reciben miles de solicitudes de restitución de tierras, el Gobierno adelanta los procesos de restitución de tierras de manera microfocalizada, es decir, se enfoca en zonas del territorio nacional, y no en la totalidad del mismo, y esto lo hace siguiendo dos criterios: (1) el número significativo de reclamantes y (2) las condiciones de seguridad para el retorno de las víctimas. Esta última condición implica que en las zonas en las cuales no existan condiciones de seguridad para el retorno de las víctimas de despojo o abandono forzado, no habrá restitución de tierras, y tratar de buscar esas condiciones de seguridad en las zonas más peligrosas llevaría más tiempo que el establecido para la aplicación de la Ley 1448 de 2011.

8. Varios problemas se generan alrededor de la aplicación de la Ley de Victimas y Restitución de Tierras, tales como el miedo de las víctimas ante las amenazas de los victimarios, la corrupción de los funcionarios en las oficinas de registro de instrumentos públicos y de los mismos jueces, la utilización de testaferros por parte de los grupos insurgentes o mafias dedicadas al despojo de tierras, los terceros de buena fe, el hecho de que los jueces especializados en restitución de tierras en su mayoría no estén siendo nombrados en propiedad, la mayor duración de los procesos judiciales a causa de los opositores, el no cumplimiento del plazo establecido por la ley de 4 meses para tramitar el proceso judicial de restitución de tierras. Estos se constituyen en los principales obstáculos para lograr una restitución de tierras efectiva, lo cual llevaría a que realmente en la mayoría de casos las víctimas sean reparadas con restitución por equivalente o con el reconocimiento de una compensación. Realmente no se lograría cumplir con una restitución en el sentido estricto de la palabra. 
9. Otro problema evidenciado es que la incapacidad del Gobierno por elaborar una ley de reforma agraria incluyente y democrática hubiera evitado en gran medida la violencia que se suscita alrededor de la tenencia y propiedad de la tierra. A pesar de que la Ley de Victimas y Restitución de Tierras solo se enfoca en restituir tierras a víctimas del conflicto armado, su aplicación tendrá como consecuencia una nueva distribución de la tierra y condiciones para su explotación, con lo cual se confunde con aspectos que son materia de una reforma agraria.

\section{Análisis de sentencias de restitución de tierras}

En el examen que realizan los jueces y magistrados especializados en restitución sobre los derechos territoriales de las víctimas despojadas, se parte en primer lugar de establecer la ocurrencia de hechos violentos en el contexto del conflicto armado interno, a partir del 1 de enero de 1985, tal como lo prescribe el artículo 3 de la Ley 1448 de 2011. Luego de comprobar la existencia de los hechos violentos que dieron lugar al abandono forzado o al despojo de tierras, se procede a declarar la nulidad de los títulos de dominio adquiridos por los usurpadores. En este sentido es importante citar un análisis de las sentencias que han sido proferidas por la jurisdicción especial de restitución de tierras.

La primera sentencia sobre restitución de tierras fue proferida el 23 de septiembre por la Sala Civil Especializada en restitución de tierras del Tribunal Superior del Distrito Judicial de Antioquia (2014). En esta providencia se dio aplicación a la Ley 1448 de 2011 y al decreto 4633 de 2011.

El punto de partida del presente análisis es la sentencia como herramienta que garantiza el reconocimiento del derecho fundamental a la restitución y a la formalización de la tierra, y en el cual el juez juega un papel fundamental. Es así como Sager (citado en Observatorio de Regulación de Derechos de Propiedad, 2013) define la sentencia como:

"Una fuente de información sobre la forma como los operadores judiciales entienden y aplican la ley, y una representación material, prueba del ejercicio mental que realiza el juez para tomar su decisión. Por ello, analizar la sentencia es de suma importancia, 
pues refiere los hechos relacionados con el despojo y el abandono forzado de tierras y da cuenta de los pasos y operaciones que se sigue a nivel judicial para otorgar la reparación" (Observatorio, 2013).

A partir del análisis de sentencias declaradas por los jueces y magistrados especializados en restitución de tierras, se hace necesario hacer mención del comportamiento de los funcionarios judiciales, así como los obstáculos y límites que enfrenta la restitución de tierras en el escenario judicial.

Es así como las sentencias se clasifican según las diferentes características y complejidades de las víctimas y sus situaciones particulares en simples, intermedias y complejas de acuerdo con los problemas jurídicos que analizan las medidas adicionales que el juez adopta y la coexistencia de diversos regímenes jurídicos (Observatorio, 2013).

Según el Observatorio de Regulación de Derechos de Propiedad (2013), las sentencias simples pueden resumirse en aquellas en las que hay poca discusión respecto del derecho de la víctima a la restitución. Algunos elementos de estas sentencias simples son: (a) las víctimas tienen una relación de propiedad formal con la tierra, contando con títulos jurídicos regulares, (b) son casos de abandono forzado mas no de despojo y (c) las víctimas ya han regresado por su cuenta al predio. En estas sentencias, los jueces dictan como medidas regulares la entrega material del bien y el acompañamiento de la fuerza pública en caso de ser necesario. Sin embargo, algunos de los jueces complementan la adopción de estas medidas (que no entrañan un efecto práctico para la víctima que ya ha retornado) con las medidas de reparación transformadora (alivio de pasivos, otorgamiento de créditos y subsidios, asistencia técnica agropecuaria, entre otras) que permiten el uso y goce de la propiedad sobre la tierra. Las sentencias de restitución se presentan entonces como la ocasión propicia para una distribución de activos rurales (Observatorio, 2013).

De acuerdo con el Observatorio (2013), en las sentencias intermedias se encuentran como elementos centrales: (a) la necesidad de que el juez estudie y acredite la existencia de un vínculo entre el solicitante y el predio, (b) la discusión frente a derechos de terceros intervinientes u opositores y (c) la tarea de establecer cuestiones sobre la titulación conyugal o la disolución de sociedades conyugales o patrimoniales. Estos elementos enunciados plantean una discusión acerca los límites de decisión del juez; 
es decir, a pesar del carácter de juez constitucional que ostenta un juez de restitución, en varios casos este enfrenta los problemas jurídicos aplicando normas propias del derecho civil, con lo cual se comporta como un juez ordinario y no como sería deseable frente a la garantía de un derecho fundamental y la discusión constitucional sobre el mismo (Observatorio, 2013).

A su vez, estas sentencias ponen en evidencia algunas dificultades adicionales de la restitución como resultado del desconocimiento y aplicación diversa de las normas sobre sucesiones o la convivencia para la unión marital. Las sentencias ponen de presente la dificultad de alegar y acreditar que la propiedad o posesión de predios en zonas afectadas por la violencia fue con completo desconocimiento de la situación de desplazamiento forzado y de despojo en muchas regiones del país. Incluso imponen cargas a los opositores que también fueron víctimas de conflicto armado y que deben demostrar la buena fe exenta de culpa.

Según afirma el Observatorio(2013), las sentencias complejas, estas son aquellas en las que: (a) el juez analiza el vínculo entre el solicitante y el predio, (b) se discuten derechos de terceros intervinientes u opositores, (c) el juez debe resolver discusiones sobre titulación conyugal, relación marital, sucesiones y, además, (c) presentan una colisión de regímenes jurídicos diversos y frente a los cuales los jueces no tienen respuestas homogéneas. Uno de los factores que puede explicar esta falta de uniformidad en las decisiones es la poca disciplina frente al precedente horizontal, la inexistente jurisprudencia de la Corte Suprema de Justicia como tribunal de cierre de estos jueces especializados o a las pocas providencias de los Tribunales Superiores en ejercicio del grado de consulta (Observatorio, 2013).

\section{Propuesta}

En Colombia desde hace aproximadamente tres años el Gobierno aplica la Ley de Víctimas y Restitución de Tierras, la cual se creó con el fin de devolverles 2 millones de hectáreas a 4 millones de personas que tuvieron que abandonar o les despojaron sus tierras mediados por la violencia a manos de miembros de grupos al margen de la ley y criminales que expulsaron a comunidades enteras, despojándolos de tierras. 
Es así como con la puesta en marcha de la Ley 1448 hay un gran avance en el reconocimiento de las víctimas, pero aún persisten diversas fallas en la Ley y bloquean el proceso. En relación con el marco jurídico que se está aplicando podría conllevar a la legitimación de muchas tierras que fueron despojadas, pero en varias de las zonas micro focalizadas no ha habido aporte económico de empresas nacionales e internacionales.

En este orden de ideas, el contenido de los fallos permite ver los indicios sobre los problemas y complejidades a los que se enfrenta el juez de restitución al abordar las solicitudes. Es así como se presentan fuertes inconvenientes en lo que tiene que ver con la interacción de varios regímenes jurídicos: la justicia transicional, el derecho de familia, el derecho de bienes y el de sucesiones, entre otros. Incluso, hay que tener en cuenta que en muchas ocasiones estos sistemas pueden resultar excluyentes los unos con los otros, obligando al operador jurídico a ponderar los intereses y derechos que están en juego, y escoger la solución más amable para las víctimas reclamantes de tierras.

En este sentido, es indispensable identificar y poner en marcha espacios tales como mesas de participación que den cuenta del compromiso por parte de los Comités de Justicia Transicional en materia de mayor participación de los servidores públicos en dichos espacios, así como su representatividad para una participación activa y condicionada al contexto territorial que garantice su presencia. Por último, los planes de atención territorial y reparación integral a las víctimas del conflicto armado, los cuales, en la mayoría de los casos, han sido elaborados sin la participación de las víctimas y mucho menos socializados con la comunidad en general.

Es importante que en el ámbito regional exista una evaluación a partir de las solicitudes de reparación administrativa, aportando conocimiento sobre el contexto local; la implementación de estrategia de divulgación a las víctimas que viven en zonas rurales y la formulación de los procesos de reparación colectiva debe hacerse con participación de las víctimas.

En esta medida se requiere: a) delimitar hacia el futuro la posibilidad de que sigan registrándose víctimas de manera indefinida en el tiempo, pues esto implica el reconocimiento de que el conflicto en Colombia no tiene fin; b) fortalecer las estrategias para la generación de ingresos por medio del mercado laboral y los emprendimientos 
productivos para el retorno y la permanencia en el territorio; c) dar celeridad al proceso de restitución desde las posibilidades de la ley sobre restitución colectivas y el fortalecimiento de las capacidades de los actores involucrados y, por último, d) crear los mecanismos para la resolución de los conflictos generados por el mismo Gobierno entre las restitución de tierras y los compradores de buena fe, las licencias mineras y la el plan de consolidación territorial.

Según Echavarría (2014), algunas de las propuestas para mejorar el proceso de restitución de tierras han sido promover la tramitación colectiva de las solicitudes de restitución de predios vecinos (permitido por la ley 1448/11), y capacitar a las organizaciones y funcionarios en todos los procedimientos y relaciones con el registro de víctimas, solicitud de restitución y específicamente para los jueces en el tema de justicia transicional (Olozaga, 2014).

Es claro que el Gobierno nacional ha avanzado en la construcción de la institucionalidad para la reparación de las víctimas y la restitución de tierras, sin embargo es necesario que el Estado continúe con la articulación inter e intrainstitucionalmente para hacer que el proceso sea exitoso y que los enormes esfuerzos presupuestales tengan un impacto claro y satisfactorio para las víctimas que han sufrido las consecuencias del conflicto y que hasta el momento no han mejorado sus condiciones de vida.

\section{Conclusiones}

La Ley de Víctimas no responde a todos los problemas jurídicos que se pudieran generar entorno a la restitución; ante esto, el juez queda a la merced de un amplio catálogo de regímenes jurídicos a partir de los cuales tomará una decisión aunque, en la práctica, se ha notado que el operador judicial tiende a valerse de aquellos regímenes donde se siente más cómodo. En este sentido, es necesario analizar que los fallos evidencian una interpretación rígida de las normas del derecho civil, pudiendo apelar a otros instrumentos, nacionales e internacionales, sobre derechos de las víctimas y a los efectos que genera considerar la restitución como un derecho fundamental que debe ser protegido, incluso por encima de las leyes ordinarias. Este hecho se refleja en la forma en la que los jueces resuelven determinadas situaciones, como en los casos de liquidación 
de sociedades conyugales o sucesiones. Adicionalmente, el asunto se vuelve más complejo cuando se considera que las órdenes emitidas por los jueces de restitución deben ejecutarse en contextos de falta de coordinación por parte de las entidades implicadas, y en que su implementación se sujeta a las limitaciones de recursos técnicos, humanos y financieros que dificultan el goce efectivo del derecho a la restitución. Y, por último, deben considerarse las condiciones de seguridad jurídica y física que han impedido culminar los procesos de entrega material y retorno a los predios.

En otros casos, los procesos de restitución coexisten con derechos de exploración y explotación de actividades minero-energética, situaciones que han sido resueltas por los jueces de forma diversa. En algunos casos el juez privilegia el derecho fundamental a la restitución y busca medidas efectivas para su garantía. En algunos casos, el juez ordena, entre las medidas adoptadas, que cualquier exploración o explotación de estas actividades deba contar con la autorización de la víctima restituida. En otros, el derecho a la restitución no es garantizado efectivamente ante órdenes que otorgan un plazo para que las autoridades competentes definan la vocación económica de predios formalmente restituidos, sometiendo la decisión de restitución y entrega material del predio a la información que suministre la entidad determinada.

En este sentido, es indispensable identificar y poner en marcha espacios tales como mesas de participación que den cuenta del compromiso por parte de los Comités de Justicia Transicional en materia de mayor participación de los servidores públicos en dichos espacios, así como su representatividad para una participación activa y condicionada al contexto territorial que garantice su presencia, la cual puede contribuir a convertirse en un ente regulador.

\section{BibLIOGRAFÍA}

Albán, Á. (2011). Reforma y contrarreforma agraria en Colombia. Revista de Economía Institucional, 13(24), 327-356. Recuperado el 23 de abril de 2015, de http://www.scielo.org. co/pdf/rei/v13n24/v13n24a11.pdf

Balcázar , Á., López , N., Orozco, M. L., \& Vega, M. (septiembre de 2001). Colombia: alcances y lecciones de su experiencia en reforma agraria. Desarrollo productivo. Recuperado el 
23 de abril de 2015, de Comisión Económica para América Latina y el Caribe: http:// repositorio.cepal.org/bitstream/handle/11362/4493/S019751_es.pdf?sequence=1

Bandieri, S. (2005). Del discurso poblador a la praxis latifundista: la distribución de la tierra pública en la Patagonia. Mundo agrario, 6(11), 25. Recuperado el 20 de mayo de 2015, de http://www.memoria.fahce.unlp.edu.ar/art_revistas/pr.540/pr.540.pdf

Bolívar Jaime, A. (17 de agosto de 2012). Dejusticia. Obtenido de Dejusticia: Derecho, justicia, sociedad: http://www.dejusticia.org/\#!/actividad/1264

Echavarria J \& Otros. (2014). Informe de la misión de estudios para la competitividad de la caficultura en Colombia. Documento extraído el 20 de junio de 2016 de http://www.larepublica.co/sites/default/files/larepublica/2014-1001\%20INFORME\%20FINAL\%20 (1)\%20ALTA\%20COMISION\%20Echavarria.pdf

El Tiempo. (13 de octubre de 2014). Los “paras”, segundo grupo involucrado en el despojo de tierras. Villavicencio, Meta, Colombia: El tiempo. Recuperado el 15 de mayo de 2015, de http://www.eltiempo.com/colombia/otras-ciudades/despojo-de-tierras-a -manos-de-paramilitares/14680788

Franco Cañas, A. M., \& De los Ríos Carmenado, I. (2011). Reforma agraria en Colombia: evolución histórica del concepto. Hacia un enfoque integral actual. Cuadernos de Desarrollo Rural, 8(67), 93-119. Recuperado el 15 de abril de 2015, de http://www.scielo. org.co/pdf/cudr/v8n67/v8n67a05.pdf

González Pulgarín, J. J., \& Henao Guzmán , J. P. (18 de Mayo de 2012). Una nueva forma de concentración de la tierra en Colombia: la Ley 1448 de 2011. Ecos de Economía(34), 75-109. Recuperado el 18 de mayo de 2015, de http://www.scielo.org.co/pdf/ecos/v16n 34/v16n34a4.pdf

González Posso, C. (13 de abril de 2013). Centro Nacional de Memoria Histórica. Obtenido de http://centromemoria.gov.co/wp-content/uploads/2013/11/15.04.13-LA-VERDAD-DEL-ABANDONO-FORZADO-Y-EL-DESPOJO-DE-TIERRAS-1.pdf

Gutiérrez Ramos, J. (Febrero de 2002). Instituciones indigenistas en el siglo XIX. Credencial Historia(146). Recuperado el 21 de Abril de 2015, de http://www.banrepcultural.org/ blaavirtual/revistas/credencial/febrero2002/indigenistas.htm

Grupo de Memoria Histórica. (2010). La tierra en disputa Memorias de despojo y resistencia campesina. Comisión Nacional de Reparación y Reconciliación. Bogotá: Ediciones 
Semana. Recuperado el 12 de Mayo de 2015, de http://www.banrepcultural.org/sites/ default/files/81461/La_tierra_en_disputa.pdf

Hernández Sabogal, M. (20 de junio de 2011). razón pública. Obtenido de razonpublica. com: http://www.razonpublica.com/index.php/regiones-temas-31/2140-ley-de-victimas-es-necesaria-la-verdad-sobre-el-despojo-de-tierras.html

Ley 100 de 1993. Ley "Por la cual se crea el sistema de seguridad social integral y se dictan otras disposiciones".

Liévano Aguirre, I. (1996). Las misiones jesuitas en el Nuevo Reino. En I. Liévano Aguirre, Los grandes conflictos sociales y económicos de nuestra historia II. Bogotá: Imprenta Nacional de Colombia. Recuperado el 19 de abril de 2015, de http://www.banrepcultural.org/ blaavirtual/historia/cseii/cseii03.htm

Malagón Pinzón, M. (2005). La historia del control de las administraciones públicas en la Colonia. Civilizar, 1-17.

Machado Cartagena, A. (1991). Problemas agrarios Colombianos. Bogotá: Siglo XXI.

Mendoza Morales , A. (1998). Tesis Agraria para Colombia. Boletín oficila de la Sociedad Geográfica de Colombia, 1-7. Recuperado el 16 de abril de 2015, de http://www.sogeocol. edu.co/documentos/tes_agr_col.pdf

Obsevatorio de Derechos de Propiedad (14 de Abril de 2013). Observatorio de tierras. Recuperado el 6 de Octubre de 2015, de Observatorio de tierras: http://www.observatoriodetierras. org/wp-content/uploads/2014/01/TENDENCIAS-DE-RESTITUCI\%C3\%93N.pdf

Olozaga, H. E. (3 de Septiembre de 2014). Análisis de la Ley de Víctimas y restitucion de tierras. Recuperado el 08 de Octubre de 2015, de Análisis de la Ley de Víctimas y restitucion de tierras: http://www.icpcolombia.org/archivos/proderural/nota_politica_3.pdf

Tribunal Superior Distrito Judicial de Antioquia, Sala Civil Especializada en Restitución de tierras. (23 de septiembre de 2014). Sentencia 27001312100120140000500 (15). MP: Vicente Landinez Lara. Recuperado el 5 de octubre de 2015 de http:// www.codhes.org/images/Articulos/Sentencia_007_del_23_de_septiembre_de_2014_ rad_27001312100120140000500.PDF

Verdad Abierta. (10 de octubre de 2012). Verdadabierta.com. Obtenido de En sus confesiones los paramilitares han revelado muy poco sobre la estrategia del desplazamiento forzado 
Verdad Abierta. (26 de noviembre de 2014). verdadabierta.com. Obtenido de http://www. verdadabierta.com/restitucion-de-bienes/5528-las-criticas-de-amnistia-internacional-ala-restitucion-de-tierras

Verdadabierta.com. (16 de septiembre de 2014). Verdad Abierta . Obtenido de http://www. verdadabierta.com/justicia-y-paz/reparaciones-a-victimas/5438-solo-el-6-8-de-reparacion-a-victimas-se-ha-pagado-con-dineros-de-desmovilizados 